\title{
Process of Digital Transformation of Agrarian Economy
}

\author{
Fedorov A.D.* \\ Rosinformagrotekh FSBSI \\ Pravdinsky Township, Moscow Region, Russia \\ e-mail: inform-iko@mail.ru
}

\author{
Kondratieva O.V. \\ Rosinformagrotekh FSBSI \\ Pravdinsky Township, Moscow Region, Russia \\ e-mail: inform-iko@mail.ru
}

\author{
Slinko O.V. \\ Rosinformagrotekh FSBSI \\ Pravdinsky Township, Moscow Region, Russia \\ e-mail: inform-iko@mail.ru
}

\begin{abstract}
The information on the state and trends of digitalization of agriculture is provided determining areas in the process of digital transformation of the economy (including agriculture) are shown. Areas of application of the Internet of Things (IoT) in agriculture, the economic effect of its implementation and development prospects are discussed. The paramount condition for the breakthrough of digital technologies in the Russian agricultural industry on the global market is the strengthening of the innovative component in the agricultural sector.
\end{abstract}

Keywords - agriculture, innovation, information technology, digitalization, the Internet of things, pilot technologies, integration, smart farms, big data.

\section{STATEMENT OF THE PROBLEM}

According to UN forecasts, it will be necessary to produce $70 \%$ more food than now to feed the growing population of the Earth by 2025 . For agriculture, this means a regular and growing demand for agricultural products, as well as the emergence of a number of new challenges and fundamentally new requirements for the level of productivity in general.

In a message to the Federal Assembly of the Russian Federation that took place on March 1, 2018, the President of the Russian Federation V.V. Putin said: “... a huge technological potential is accumulating in the world today, which allows making a real breakthrough in improving the quality of life of people, in upgrading the economy, infrastructure and public administration. How effectively we can use the colossal capabilities of the technological revolution, how we respond to its challenge, it depends only on us. And in this sense, the coming years will be crucial for the future of the country. I emphasize this: they will be just crucial."

The era of digital globalization is coming to be defined by data streams that contain information, ideas and innovations. According to expert forecasts, by $2020,25 \%$ of the global economy will switch to the introduction of digitalization technologies that enable the state, business and society to function efficiently. The developed countries, having completed industrialization, are successfully upgrading their economies. They are rapidly developing innovative technologies dominated by artificial intelligence, automation and digital platforms. Global spending on research and development is about 2 trillion USD with an average annual growth of $4 \%$ [1].

The State Program titled "Digital Economy of the Russian Federation" approved by Order No. 1632-r of the Government of the Russian Federation dated July 28, 2017, states: “... digital data is a key factor in production in all areas of socioeconomic activities, which increases the country's competitiveness, the quality of life of citizens, ensures economic growth and national sovereignty" [2].

Currently, in order to ensure the sustainable development of the agricultural sector of the economy and food independence of the country and to increase export potential, it is necessary to turn the agricultural sector into a competitive hightech industry with high labor productivity and low overhead costs. This requires a technological breakthrough, an integral part of which is the introduction of digital technologies in the agricultural production. This determines the relevance of this study.

\section{RESEARCH PURPOSE}

The purpose of the research is to analyze the current state of digitalization of agriculture, identify the determining areas in the process of digital transformation of the economy (including agriculture) and the prospects for the development of IoT technology in agriculture.

\section{MATERIALS AND RESEARCH METHODS}

In conducting the research, informational materials were used, including those obtained from the websites of the Ministry of Agriculture of Russia, Russian and foreign organizations, where the research results and information on digitalization of agriculture had been presented. Their analysis and generalization have been performed. 


\section{RESEARCH RESULTS AND DISCUSSION}

According to the materials of the International Independent Institute of Agrarian Policy, the key trend in the global economy of the last decade is the widespread adoption of digital technologies. The industry standard in agriculture is the use of geolocation systems, integrated fleet management, precision farming, but the level of introduction of digital technologies in the agricultural industry remains low. The world leaders in the implementation of digital technologies are IT companies, media, financial and insurance companies, and logistics. The lowest implementation level is in agriculture (Fig. 1) [3]

Source: McKinsey \& CBINSIGHT

\begin{tabular}{|c|c|c|c|c|c|c|}
\hline & $\begin{array}{l}\text { Orerall digital } \\
\text { technology } \\
\text { adoption level }\end{array}$ & Asset management & Transactions & Business-processes & Sales & Working processes \\
\hline $\begin{array}{l}\text { Information } \\
\text { technology }\end{array}$ & & & & & & \\
\hline Media & & & & & & \\
\hline $\begin{array}{l}\text { Finance and } \\
\text { insurance }\end{array}$ & & & & & & \\
\hline Wholesale & & & & & & \\
\hline $\begin{array}{l}\text { Hi-tech } \\
\end{array}$ & & & & & & \\
\hline Oil and gas & & & & & & \\
\hline $\begin{array}{l}\text { Production } \\
\text { commoditi }\end{array}$ & & & & & & \\
\hline Logistics & & & & & & \\
\hline Construction & & & & & & \\
\hline Agriculture & & & & & & \\
\hline
\end{tabular}

Fig. 1. Comparative level of digital technology implementation in various sectors of the global economy

According to the Ministry of Agriculture of the Russian Federation, currently, only 10-15\% (one fifth) of arable land are tilled in Russia using digital technologies. Moreover, the non-use of new technologies leads to a loss of up to $40 \%$ of the crop. Presumably, by 2026, the market for information and computer technologies in agriculture should grow at least five times, including through the support of agricultural startups [4]. Today, the Russian agricultural industry takes 15 th place in the world in terms of the level of digitalization [5].

If we consider the foreign experience in introducing digital technologies in the agricultural sector, the total global investment in digital technologies for agriculture has already reached 10.1 billion USD over the past 5 years. So far, Russia occupies only $1.5 \%$ of the global Internet of things, while the share in agriculture is even lower. Increase in investment will open up new opportunities for digitalization of agriculture [6].

The Ministry of Agriculture of the Russian Federation proposed the project titled "Digital Agriculture", the objective of which is the introduction of measures for the use of digital technologies in the agricultural sector.

At the end of 2018, the Ministry of Agriculture of Russia developed a departmental project titled "Digital Agriculture", the objective of which is the digital transformation of agriculture with the introduction of digital technologies and platform solutions to ensure a technological breakthrough in agriculture and achieve productivity growth. The project provides for the digitalization of not only business entities, but also the agricultural management system itself. The objectives of the "Digital Technologies" area are to achieve the following indicators by 2024: 30 completed projects in the field of the digital economy (at least 100 million rubles); 10 Russian organizations involved in the implementation of large projects ( 3 million USD) in priority areas of international scientific and technical cooperation in the field of digital economy [7].

A number of modern trends testify to a radical change in the situation in agriculture in the coming years. The development and production of robotic agricultural machinery are at the forefront of innovation now.

The evolution of agriculture and agricultural technology indicates a shift from Precision Farming to Digital Farming, i.e. agricultural production systems based on modern knowledge. The Digital Farming, apart from the Precision Farming technology, uses smart networks and data management tools. To make digital farming real, two basic conditions must be in place. First, these are smart machines: machines must be able to receive, send, generate (through sensors) and process data. Second, these are connected machines: communication and interface standards should ensure unhindered data exchange between machines, with business partners, and between portals. The further evolution of agriculture involves unmanned operations and autonomous decision-making systems. Agriculture will be based on robotics and (in some form) artificial intelligence [8].

Thus, the following key stages (trends) can be distinguished in the development and implementation of digital technologies in agriculture: 
Pilot technology: From the mid-2000s, the technologies of geolocation, monitoring of the state of agricultural machinery, etc. began to be introduced.

Market saturation: Currently, the number of digital technologies and industry standards in agriculture has reached a critical mass. Almost all equipment manufacturers offer their own programs and solutions that optimize the use of their machines and equipment. There are several solutions related to precision farming. A variety of options for using geodata for crop forecasting, optimization of agricultural operations, logistics management, etc. are offered. The arrival of a new generation of agricultural technologies - the Internet of things and blockchain - has an additional impact on the user.

Integration as a key trend of the future: The leader in digitalization of agriculture will be these companies that can offer common standards and solutions, which combine existing projects in the field of digital agricultural technologies and remove the problem of choice, and associated risks [3].

The economy of joint consumption is a competitive environment without intermediaries, where the seller and the buyer are at the forefront. Business models of digital platforms are built based on global user data, which allows improving content and service, attract even more users and quickly increase capitalization using breakthrough technologies including artificial intelligence. At the same time, global, large digital companies become the owners of the data, and the product is often not specifically the service provided by such platforms, but the data themselves, which causes the disappearance of cash flows from these relations [9].

It follows from the above that two areas are decisive among the important areas in the process of digital transformation of the economy (including agriculture): robotization (including the use of UAV) and work with the socalled "big data" including the development of artificial intelligence systems.

According to the International Federation of Robotics (IFR), the appearance of one robot per 1 million working hours increases labor productivity by $0.04 \%$. Savings in operating costs from automation in general can range from $15 \%$ to $90 \%$ depending on the industry. According to BCG, the market for robotics will reach $\$ 87$ billion by 2025 , with nearly a third of the market going to products for commercial use. The main factors of the dynamics will be a gradual decrease in prices for robotic equipment, high demand for products and an increase in investment [10].

The special importance of the accelerated development of these areas of digitalization for the Russian agricultural sector is due to the fact that this will not only dramatically increase the efficiency of agricultural production, but also significantly reduce the number of workers needed to produce the required amount of agricultural products. This circumstance may be decisive for bridging the existing gap in the efficiency of agricultural production between Russia and advanced agricultural countries [11].

Given the processes occurring in developed foreign countries for the technification of agricultural production, in order to ensure competitiveness in global markets, the Russian agricultural sector needs to rapidly increase the level of digitalization using the latest advances in information technology.

The Internet of Things (IoT) is one of the most effective tools to achieve a new level of digitalization [9]. IoT is a network of Internet-related objects that can collect data and exchange data from embedded services.

According to the PwC Digital IQ Worldwide Survey, in 2019, the IoT technology ranked first among eight breakthrough technologies (36\%) being ahead of artificial intelligence $(30 \%)$, robotics $(11 \%), 3 \mathrm{D}$ printers $(7 \%)$, supplemented reality $(6 \%)$, technology related to the creation of UAV and their control (4\%), blockchain (3\%), and virtual reality $(2 \%)$ (per cent of the number of respondents) [12].

Moreover, IoT is the first in the ranking taking into account the level of investment in new and promising technologies and considering their investment attractiveness (percent of the number of respondents): Internet of things (73\%), artificial intelligence $(54 \%)$, robotics $(16 \%)$, 3D printers $(12 \%)$, additional reality $(10 \%)$, virtual reality $(7 \%)$, $\operatorname{UAV}(5 \%)$, and blockchain (3\%) [12].

Smart Agriculture aims to automate agricultural activities as much as possible, increase productivity and improve product quality.

Precision farming (GLONASS, GPS, sensors, UAV) is designed to optimize operating costs and increase yields (on average by 15 to $20 \%$ ), which are achieved by: reducing the amount of seeds, agrochemicals, fertilizers and water to be used (use "on demand"); more efficient use of land: taking into account the characteristics of a particular plot, the agricultural crop with the highest yield is determined, as well as the optimal method of cultivation and care to maximize yield.

When using smart greenhouses (sensors, devices and software for remote control of greenhouses), operational savings are achieved by more efficient consumption of fertilizers, chemicals, as well as water. The technology also allows optimizing the number of staff needed to care for crops and reduce losses due to human factors.

Smart farms (sensors, devices and monitoring software) can improve animal productivity and product quality. According to market experts, automated systems for feeding, milking and monitoring livestock health can increase milk production by 30 to $40 \%$.

Monitoring of vehicles using GLONASS, GPS and sensors can reduce fuel consumption (experts predict a possible reduction of up to $20 \%$ ), as well as optimize routes and staff workload.

The issue of preservation of raw materials in the process of their collection and movement also remains relevant: sutable sensors make it possible to fully monitor both the location and weight of the raw materials moved.

Raw materials management (sensors, devices and monitoring software) is designed to reduce losses (up to $25 \%$ ) due to non-optimal storage conditions for agricultural 
products. Specially defined algorithms in real time monitor the condition of products (in particular, the ambient temperature in storages, humidity, and carbon dioxide content) and help to decide on the need for sale and/or further processing.

Effective management of agricultural raw materials: Thus, Rusagro, one of the most active participants in the Russian agricultural sector in the field of digital technology implementation, has for the first time tested and successfully implemented the technique of effective management of agricultural raw materials (storage of sugar beets).

After harvesting, sugar beets need to be stored for some time for ripening, as well as for the subsequent distribution of raw materials between plants for processing. Effective storage requires a certain temperature and humidity.

Rusagro has developed algorithms supported by IoT (wireless temperature, humidity, and carbon dioxide sensors). Sensors automatically monitor the state of the environment and raw materials while transmitting information to receiving devices; a computer platform aggregates these data, consolidates them with weather reports and determines and/or decides on the optimal level of readiness of a particular batch for processing and the sequence of its submission to production.

This allowed reducing the level of raw material losses (by $20 \%$ ) and increase final production efficiency.

Other digital transformation tools of the company are the entire fleet equipment with sensors (GPS-tags, fuel consumption measurement, etc.). Currently, the company is implementing a number of pilot projects in other areas of IoT: precision farming and farm management (automation of pig farms).

The company is actively developing not only collecting the maximum amount of data, but also their further coordination and analysis.

Big data: To harvest a quality crop, it is necessary to integrate a huge amount of different information: weather conditions, soil moisture, seed quality, lighting, quality of plowing, etc. The system can offer certain optimized planting scenarios to increase the final productivity by downloading these data and integrating them into the system while setting certain algorithms.

The evaluation of economic efficiency from the implementation of IoT: The total minimum economic effect of the introduction of IoT in agriculture can be about 469 billion rubles for the period up to 2025 due to: reduction of losses of raw materials (grain) (195 billion rubles); optimization of personnel costs (188 billion rubles; reduction of losses of fuels and lubricants (86 billion rubles) [12].

Minimizing the losses that market players are currently suffering is only one component of the IoT economy. The potential long-term effect is wider. It is associated with:

- Cost optimization (due to the saving of consumables and resources), which affects the margin and, as a consequence, the competitiveness of companies
- New opportunities to increase revenue due to increased yields (according to various estimates, from 10 to $20 \%$ ) and to improve product quality.

The key challenges for Russian farmers are the growth of domestic and foreign demand for agricultural products, as well as the need to increase labor productivity and competitiveness. However, these challenges will inevitably be a driver for the technology of the industry.

In general, IoT technologies in agriculture are being implemented pointwise and mainly by large companies in the Russian Federation taking into account both the general technological lag of the agricultural sector, and the low level of labor productivity.

According to some of the largest Russian companies, IoT will make it possible to make a breakthrough in the industry and enter a new level of competition. Smaller companies use technology in a significantly limited format while seeing in it a tool to reduce production costs.

According to experts, technologies for monitoring and control of machinery and precision farming technologies will have the greatest potential.

In addition, the introduction of IoT will become a driver for the development of new related markets, such as the markets for the production of unmanned aerial vehicles, autonomous agricultural equipment, etc.

In accordance with the roadmap for the development of IoT in the agricultural sector, the share of agricultural enterprises using IoT solutions should be $30 \%$ by 2019 , and $35 \%$ by 2020.

However, according to experts of the agricultural market, there are some barriers that limit the speed and reduce the efficiency of technology distribution in the industry:

Communication and infrastructure: The farmland of the Russian Federation is poorly covered by communication networks that would ensure the transmission of data from various IoT devices in real time. On the part of telecom operators, substantial investments are required in the construction of the corresponding infrastructure, such as antenna mast structures and communication lines. Here, the government can help accelerate the implementation of IoT in the industry, for example, by reducing and/or subsidizing the cost of land for the placement of communication facilities.

Localized IT Solutions: There are currently no comprehensive, well-developed localized IT solutions for implementation on the Russian market. There are many individual proposals, however, enterprises face difficulties in adapting these solutions to their needs and integrating solutions among themselves.

According to analysts, up to 100 million connected Internet of things devices are expected in agriculture by the end of 2020 [13]

The ISBC group of companies has certified domestic radio-frequency identification (RFID) with the International Committee for Animal Recording (ICAR). RFID is designed 
for automated identification and registration of animals. The products of Zelenogradsk ISBC plant have successfully passed all tests for compliance with ISO 11784 and ISO11785 international standards. Currently, Russia independently produces certified RFID for animals. Clear identification of sick animals will allow timely identification of infected products, including imported ones, to prevent epidemics of dangerous diseases, which will ensure food security.

RFID will provide $100 \%$ control. The entire path of products "from the field to the table" will become transparent, and there will be confidence in the health of the cow depicted on the milk package. The Internet of Things will be put into practice in a simple technology that every person needs.

The Agency for Strategic Initiatives (ASI), together with the business community, presented in September 2017 a roadmap for the development of the FoodNet (smart agriculture) food market, which was a part of the National Technology Initiative (NTI).

In accordance with the roadmap, Russian companies should occupy more than $5 \%$ of the world market in five priority segments by 2035 . These include smart farming (automation, artificial intelligence, and big data are used in production), accelerated breeding, accessible organics, as well as new sources of raw materials (processing, for example, of biomass of algae and insects, introduction of pseudograin crops, etc.), and personalized feeding [13].

FoodNet also includes infrastructure projects (creating a network of agricultural clusters, creating a monitoring system in the agribusiness using big data), as well as educational and regulatory projects.

As noted in the roadmap, the implementation of FoodNet will achieve the goals set in the strategy for scientific and technological development: the transition of the Russian agricultural sector to high-tech production and reduction of dependence on imports, as well as the entry of Russian companies into promising world markets.

The roadmap identifies seven priority projects, which are also related to the priority projects of NTI. Their total cost is about 3.3 billion rubles; about 2.2 billion rubles are planned to attract from the federal budget in the form of grants and repayable forms of financing until 2021. However, it is assumed that FoodNet projects should be developed primarily through private investment.

Such a segment as smart agriculture should show the highest growth rates: the average annual market growth can reach $12 \%$, and the market size will reach 480 billion USD in 20 years (for comparison: 46 billion USD in 2015). Russia has competitive technologies in this field (including GLONASS), and companies and organizations with significant experience in this field, such as Rostselmash, Geomir JC, Agroinnovation LLC, etc. [14].

The introduction of digital technologies in the agricultural sector of the Russian economy will be facilitated by the maximum automation of all stages of the production cycle in order to reduce losses and increase productivity, by optimization of the resource management based on decisions made as a result of processing big data streams that are effectively processed by scalable software tools and database management systems [15]. Therefore, the paramount condition for the breakthrough of digital technologies in the Russian agricultural industry on the global market is the strengthening of the innovative component in the agricultural sector.

\section{CONCLUSIONS}

1. To transform the Russian agrarian sector of the economy into a competitive high-tech industry with high labor productivity and low unproductive costs, a technological breakthrough is required, an integral part of which is the introduction of digital technologies in the agricultural production.

2. The developed countries, having completed industrialization, are successfully upgrading their economies, developing innovative technologies at an accelerated pace, where artificial intelligence, automation and digital platforms dominate. According to expert forecasts, $25 \%$ of the global economy will switch to the introduction of digitalization technologies by 2020, which will enable the state, business and society to function efficiently.

3. Given the processes occurring in the developed foreign countries for the technification of agricultural production, in order to ensure competitiveness in global markets, the Russian agricultural sector needs to rapidly increase the level of digitalization using the latest advances in information technology.

4. The Internet of Things is one of the most effective tools to achieve a new level of digitalization.

5. Implementation of the "Digitalization of Agriculture" program will contribute to raising the level of technological development of agricultural production.

\section{References}

[1] G. Eason, B. Noble, I.N. Sneddon, "On certain integrals of LipschitzHankel type involving products of Bessel functions", Phil. Trans. Roy. Soc. London, vol. A247, pp. 529-551, April 1955. Retrieved from: http://kzvesti.kz/kv/thirdband/25528-cifrovizaciya-apk-trebovanienovogo-vremeni.html (accessed on: 04/10/2020).

[2] "Digital Economy of the Russian Federation" program, approved by Order of the Government of the Russian Federation dated 28 July 2017, no. 1632-r. Retrieved from: http://static.government.ru/media/files/ 9gFM4FHj4PsB79I5v7yLVuPgu4bvR7M0.pdf (accessed on: 04/04/2020).

[3] Trends in digital technologies in the agricultural sector. Retrieved from: http://mniap.rf/analytics/Trendy-cifrovyh-tehnologij-v-APK/ (accessed on: 04/11/2020).

[4] Digitalization of agriculture. Retrieved from: http://polit.ru/article/ 2018/02/21/sk_digital_farming/ (accessed on: 04/11/2020).

[5] The Digital transformation of agriculture conference was held in Moscow. Retrieved from: http://mcx.ru/press-service/news/v-moskvesostoyalas-tsifrovaya-transformatsiya-selskogo-khozyaystva/ (accessed on: $04 / 17 / 2020$ )

[6] The Ministry of Agriculture is developing a Digitalization of Agriculture Program. Retrieved from: https://agrarian.rf/index.php?Id=422 (accessed on: 04/10/2020).

[7] A.N. Lysenko, "On the issue of digitalization of agriculture", Agrar. Ed and sci., no. 2, p. 10, 2019.

[8] A.I. Belenkov, "Digital farming”, Nivy Rossii, no. 10, pp. 52-58, 2017. 
[9] M. Mishustin, "Developing digital startups", Newsletter, no. 3, pp. 8-9, 2020.

[10] "Newsletter of the Ministry of Agriculture of the Russian Federation", no. 3, pp. 8-9, 2020.

[11] N.R. Kelchevskaya, E.V. Shirinkina, "The influence of digital technologies of industries on the potential economic effect", World of Econ. and Manag., vol. 19, no. 2, pp. 19-30, 2019.

[12] S.G. Salnikov, Actual areas of digital transformation of the agricultural sector of Russia. Retrieved from: http://www.viapi.ru/ (accessed on: 04/14/2020).

[13] The Internet of Things (IoT) in Russia. Future technology available now. Retrieved from: https://www.pwc.ru/ru/publications/iot/IoT-inRussiaresearch_rus.pdf (accessed on: 04/04/2020).

[14] "IT in the agricultural sector of Russia," Retrieved from: http://www.tadviser.ru/index.php/\%D0\%A1\%D1\%82\%D0\%B0\%D1\%82 (accessed on: 04/04/2020).
[15] A.D. Fedorov, O.V. Kondratiev, O.V. Slinko, V.A. Voytyuk, "Digitalization of agriculture is the key to successful development of the industry", pp. 69-73, 2019 [State and Prospects for the Development of the Agricultural Sector, Proc. of the XII Int. Sci. and Pract. Conf. as part of the XXII Agro-Industr. Forum of the South of Russ. and the Interagromash Exhibit.]. Don State Technical Univer.; Don Agricult. Res. Center.

[16] T.E. Marinchenko, "Digitalization as a driver of technological development of the agribusiness", pp. 30-34, 2019 [State and prospects of development of the agribusiness, Proc. of the XII Int. Sci. and Pract. Conf. as part of the XXII Agro-Industr. Forum of the South of Russ. and the Interagromash Exhibit.]. Don State Technical University; Don Agricultural Research Center. 